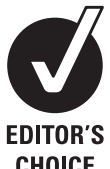

CHOICE

- Supplementary figures are published online only. To view these files please visit the journal online (http://mh.bmj. com).

${ }^{1}$ College of Public Health, The University of Nebraska Medical Center, Omaha, Nebraska

${ }^{2}$ Otolaryngology, Head and Neck Surgery, The University of Nebraska Medical Center, Omaha, Nebraska, USA

${ }^{3}$ The University of Nebraska Medical Center, Omaha, Nebraska, USA

Correspondence to Dr Virginia A Aita, Associate Professor, College of Public Health, The University of Nebraska Medical Center, 986075 Nebraska Medica Center, Omaha, Nebraska, 68198-6075, USA: vaita@unmc.edu

Accepted 13 April 2010

\title{
Portraits of care: medical research through portraiture
}

\author{
Virginia A Aita, ${ }^{1}$ William M Lydiatt, ${ }^{2}$ Mark A Gilbert ${ }^{3}$
}

\section{ABSTRACT}

The Portraits of Care study used portraiture to investigate ideas about care and care giving at the intersection of art and medicine. The study employed mixed methods involving both qualitative and quantitative research techniques. All aspects of the study were approved by the Institutional Review Board. The study included 26 patient and 20 caregiver subjects. Patient subjects were drawn from across the lifespan and included healthy and ill patients. Caregiver subjects included professional and familial caregivers. All subjects gave their informed consent for the study and the subsequent exhibition of artwork. The artist drew or painted 100 portraits during the 2-year study. A multi-disciplinary analysis team carried out the initial analysis of portraits and subject data. Findings from their qualitative analysis were used to develop a quantitative survey and qualitative journal tool that the public used to give feedback at the subsequent exhibition. Exhibition data confirmed the initial findings. Study results showed the introspection of subjects that revealed their sense of identity and psychological status. Patients appear as 'whole people', not fragmented by diagnosis. Caregivers' portraits reveal their commitment to care. There is also a sense of mutuality and fluidity in the background stories of subjects. Many patient subjects have been caregivers and, at times, caregivers are also patients. Public data emphasised the identity transformation of subjects, the centrality of the idea of mortality, the presence of hope despite adversity, and the importance of empathy and compassion in care.

\section{INTRODUCTION}

In the Patient and Caregiver Portraiture Study, (PCPS) clinical investigators and a portrait artist explored notions of care and care giving at the intersection of art and medicine. The idea for the study germinated after the successful Omaha, Nebraska exhibition Saving Faces: Art and Medicine of artist Mark Gilbert's works that were commissioned by maxillofacial surgeon Iain Hutchison in London showing the latter's patients before and after their surgeries. When the opportunity arose to engage Gilbert in an Omaha artist residency, the authors developed a research study with the primary objective of using portraiture to better understand the human dimensions of care that might enhance the patient and caregiver experience. As part of an artist in residence programme, the artist (MG) drew and sometimes painted life size portraits of patients and caregivers. Patient subjects included both healthy and ill patients from birth to the end of life. Caregiver subjects included both familial and professional caregivers.

This manuscript reports on the overall findings of the portraiture study, including the multi-disciplinary team findings and the subsequent public exhibition findings. This manuscript does not report directly on the exhibition and events that attended it which are described elsewhere. ${ }^{1}$ The University of Nebraska Medical Center Institutional Review Board approved all aspects of the study and exhibition.

\section{BACKGROUND}

The PCPS is unusual in its use of the visual arts as a medical research medium. A background literature search of multiple health related databases uncovered five articles describing similar artist residencies in clinical settings. Only three of these articles roughly corresponded to the artist residency that resulted in the study we conducted. Of those, only one residency took place in the USA. In these three articles, authors claimed that the residency promoted an enhanced understanding of health, disease and therapeutics including positive psychological health effects for the subjects who participated. Rockwood ${ }^{2}$ stated that the Dalhousie programme with Alzheimer's patients helped promote greater scientific understanding of the role of human cholinergic neurotransmission in addition to humane therapeutic insights. Robb, ${ }^{3}$ an artist in residence at Dalhousie brings her art to the intersection of medical technology and the brain to bring a greater appreciation of ethical questions in healthcare. Graham-Pole ${ }^{4}$ claimed that the positive effects of combining art and science led to the establishment of an artist residency at his hospital institution. A separate search of research studies using the visual arts uncovered only one article in which Rebok et al reported on a paediatric study using visual cartoons and other visual cues to evaluate children's perceptions of their own health status. In a related, but non-research article, Heckmann ${ }^{6}$ discussed the artistic meanings of facial wrinkles as they have been depicted by artists through history, raising biomedical ethical questions about the contemporary meaning of wrinkles and dermatologic practices to remove them. The dearth of published material on the potential therapeutic benefits of artist residency programmes and the use of visual arts as a research methodology suggests that this study and its findings are rather unique.

\section{METHODS \\ Project design}

The study was designed to consist of two phases, the artistic component and the exhibition. During the former, investigators recruited patient and caregiver subjects from their own practices, from personal acquaintances or from other colleagues, and invited 
them to participate. Subjects included both healthy and ill patients across the entire lifespan, including hospitalised and outpatients and caregivers of many types, both familial and professional. Recruitment promoted inclusion of subjects of various ages and races.

\section{Informed consent procedures}

When a patient or caregiver subject was identified, one or two of the investigators would visit the subject to explain the aims of the study and its procedures. All subjects invited to participate granted consent with three exceptions. Two surrogates of subjects refused to consent, including the Hispanic mother of a premature infant and the African American son of a man with dementia whom we hoped would be able to participate. A third white subject initially consented, but later passively withdrew. If a subject wanted to participate, investigators reviewed the entire consent document with him or her, describing the personal information that would be collected and how it would be used, details and schedule of the actual drawing/painting session(s), and the eventual uses of the art works and their exhibition(s). Each subject selected a 'name' for his/her portrait, usually the subject's first name.

\section{Portrait creation (artistic) phase}

Artist MG observed and drew or painted patients and caregivers. These works served as the basis for study. Each portrait session lasted a minimum of one hour. The time of the session was individually arranged between the artist and subject. If the artist wanted to develop more drawings or a painting and the subject was willing, the artist would schedule additional sessions. Many subjects posed multiple times. Drawing and painting sessions were conducted in a laboratory space adjacent the hospital. Subjects simply sat in a chair and were encouraged to be comfortable, not to pose as for a photograph. Subjects were given rest periods whenever desired. In cases where the artist desired to do a subject's painting, the artist took photographs to assist in the process. Subjects consented to having photographs taken, if needed, during the consent process. During the drawing session, subjects were asked to fill out a standardised data collection form (figure 1, available online at http://jmh.bmj. com). This information provided critical contextual background information for each portrait.

Each session gave the artist and sitter time to build a relationship over the period it took to work on the images. From the artist's point of view, the developing relationships were an essential part of the artistic process, informing and enhancing the images as they were created. Relationship development also gave subjects the opportunity to discuss the project with the artist, reflect on their own situations, and enquire about other subject's portraits in the studio. The artist's relationships with subjects mirrored relationships that develop between patients and caregivers.

In regard to the artistic considerations, MG made a conscious decision, when constructing and composing the images, to try to jettison anything that felt extraneous or irrelevant. There is no reference in the pictures to the room or environment where the sittings took place. The only prop that appears in some pictures is the chair or stool on which the subject was sitting. It was also a conscious decision to try to leave out any overt reference as to who were the patients and who were the caregivers. There are three exceptions, 'Jean', an obstetrician was depicted in her white coat; 'Glenna', a patient has a naso-gastric tube; and, 'Roger', a patient with advanced Amyotrophic Lateral Sclerosis (ALS) is shown ensconced in his wheel chair which is

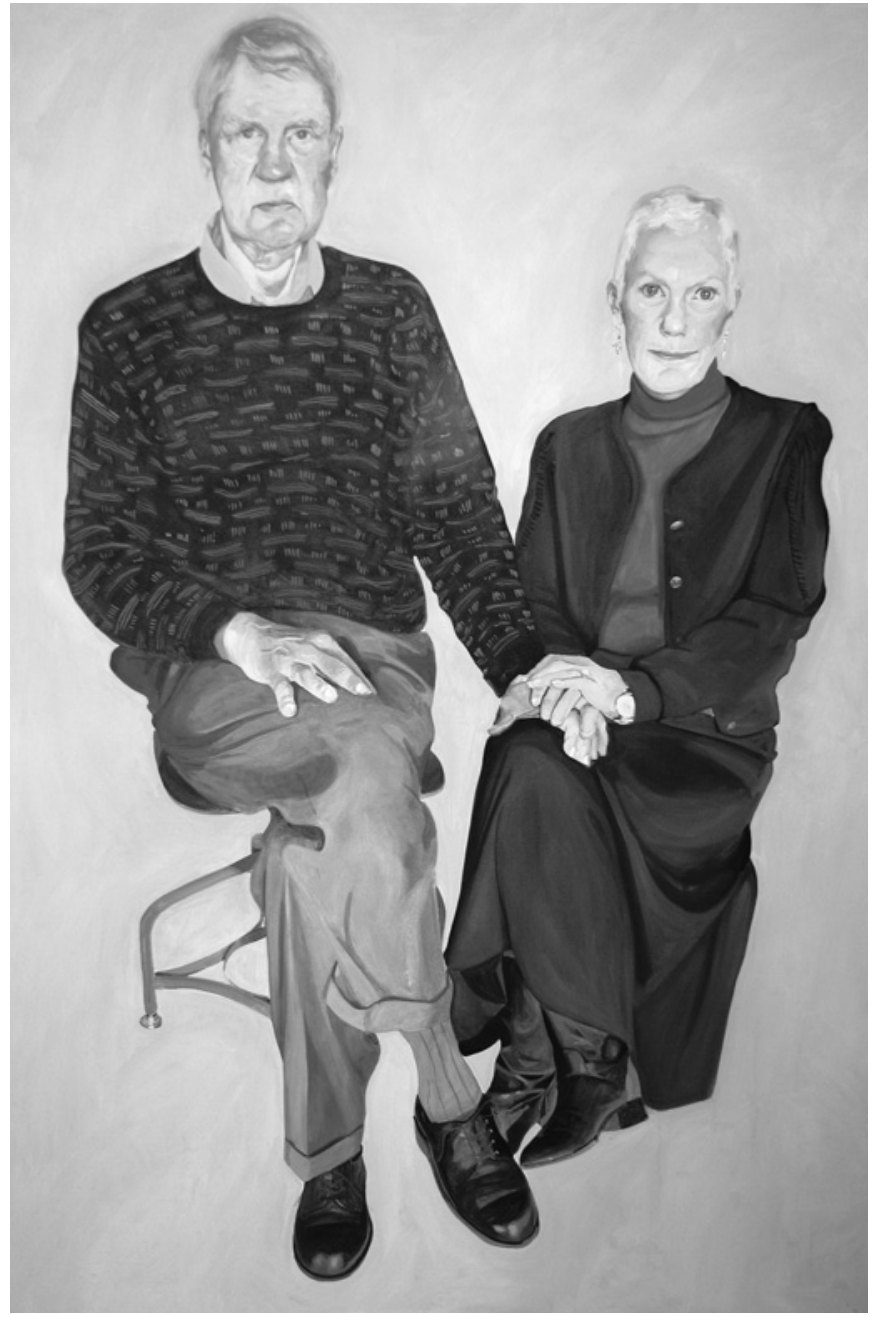

Figure 1 Mardi and Rob.

augmented with the technology that helped him survive and communicate. He was also wrapped in his US Air Force blanket, which does allude to his past life as a military navigator. These prompts create an extra narrative that is not consistent with the other portraits. These three portraits were done relatively early in the study as investigators were refining their methodology.

\section{Exhibition phase}

The exhibition Here I Am and Nowhere Else, Portraits of Care was shown at the Bemis Center for Contemporary Art, 12 December 2008 to 21 February 2009. Exhibition viewers saw only the portraits. Very little text was mounted on exhibition walls. If viewers wished to read short narratives about the subjects, they could take laminated text with them that briefly told each subject's story. It was decided that this would be the best method to display the data rather than have the text next to the portraits, which for some viewers, might detract from the images.

The exhibition phase consisted of: (a) collaboration with the Bemis Center for Contemporary Arts to plan, curate and launch the exhibition; (b) development of public educational events that were held in conjunction with the exhibition; (c) development of the gallery survey-journal data collection tool; and (d) public data collection and data analysis. Parts (a) and (b) are described elsewhere. ${ }^{1}$ In regard to the 'survey-journal' instrument, investigators consulted an expert in survey design with 
Table 1 Subject demographics by gender, race and age status (adult, child under 14, infant under 1 year) and comparative county demographic data for 2008*

\begin{tabular}{|c|c|c|c|c|c|c|c|c|c|}
\hline \multirow[b]{2}{*}{ Subject group } & \multicolumn{2}{|l|}{ Gender } & \multicolumn{4}{|l|}{ Race } & \multirow{2}{*}{$\begin{array}{l}\text { Adult } \\
\text { F/M }\end{array}$} & \multirow{2}{*}{$\begin{array}{l}\text { Child } \\
\text { F/M }\end{array}$} & \multirow{2}{*}{$\begin{array}{l}\text { Infan } \\
\text { F/M }\end{array}$} \\
\hline & Total males & Total females & $\overline{\mathbf{W}}$ & B & H & Other & & & \\
\hline Patients & $12(46.2 \%)$ & $14(53.8 \%)$ & $23(88.5 \%)$ & $2(7.7 \%)$ & 0 & $1(3.8 \%)$ Native Amer. & $10 / 11$ & $2 / 0$ & $2 / 1$ \\
\hline Caregivers & $8(40 \%)$ & $12(60 \%)$ & $17(85 \%)$ & $1(5 \%)$ & $1(5 \%)$ & $1(5 \%)$ Asian & $20 / 8$ & 0 & 0 \\
\hline $\begin{array}{l}\text { US Census Demo-graphic data } \\
\text { for county (2008) }\end{array}$ & $49.4 \%$ & $50.6 \%$ & $83.2 \%$ & $11.7 \%$ & $9.8 \%$ Hispanic or Latino & $\begin{array}{l}\text { Native Amer. }(0.8 \%) \\
\text { Asian }(2.5 \%)\end{array}$ & & & \\
\hline
\end{tabular}

*Taken from US Census Bureau data for Douglas County, Nebraska, 2008. http://quickfacts.census.gov/qfd/states/31/31055.html.

Gallup University to construct an instrument of 16 questions incorporating the original findings aside a 5-point Likert scale of 1 (strongly disagree) to 5 (strongly agree). (See figure 2, available online). On the back of the survey tool, exhibition viewers were asked to respond with short phrases or words in response to questions about artworks in the 'journal' section of the survey.

Investigators obtained a waiver of consent from the Institutional Review Board to obtain this anonymous public data. The survey was available to all exhibition patrons. The exhibition data included quantitative and qualitative components. Findings from the public data were used to confirm or reject the original qualitative study findings. Gallery patrons were invited to fill out the instrument on a strictly voluntary basis in the gallery.

\section{Data sources summary}

At the completion of the study, data included 100 pieces of artwork. The vast majority of these were charcoals on paper and canvas. Some oil paintings on canvas and 30 oils on aluminium were executed as well. All artworks were carried out in the presence of the subjects. Data also included brief narratives from all subjects about their experiences with care, care giving, health and illness as well as their thoughts about the study process. In addition, data included documents for and about the study and its processes, notes from analysis sessions and survey data of exhibition viewers.

\section{Study analysis}

Qualitative analysis began immediately during the artistic phase as the artworks began to accumulate. This analysis was carried out by a multidisciplinary team consisting of the investigators and several colleagues drawn from the disciplines of art practice, art criticism, medicine (including psychiatry and surgery), nursing, ethics and qualitative research. Analysis centred on what the portraits revealed about care and care giving in the context of health and illness. As described above the initial findings were used to construct the public data collection instrument. Biostatistics personnel at the University of Nebraska Medical Center conducted the quantitative analysis of the survey data. An independent analysis of the qualitative exhibition data was also conducted. Finally, investigators re-reviewed all study data, artistic phase and exhibition phase findings, and reconciled overall results.

\section{RESULTS FROM ARTISTIC PHASE ANALYSIS Demographic analysis}

At its conclusion, the study included 46 subjects, 26 patients and 20 caregivers. An overview of the demographics of patient and caregiver subjects with comparative US Census Bureau county demographic data are described in table 1.

These data were not collected from subjects, rather they are based on investigators' knowledge of subjects. Racial representation in both patient and care giver categories for white subjects was slightly greater and for black and Hispanic subjects lower than comparative county data for the area would suggest.
Table 2 contains the mean and SD of age (calculated by taking 2009 minus the birth year), and the frequency and percentages of diagnosis/condition for patients.

Table 3 contains the mean and SD of age (calculated by taking 2009 minus the birth year) and roles and genders of caregivers.

While professional caregiver data, including public health, appears to be about equal in terms of gender distribution, familial caregiver data supports the common expectation of women assuming more care giving roles within the family than men.

\section{Portrait analysis}

During the artistic phase of the project, investigators focused on the portraiture and its interpretation by the multi-disciplinary analysis team. The team also noted the correspondence of the portraits with subjects' data. Four themes concerning care as a non-instrumental, holistic process of engagement stood out. These included: (a) the introspection of patient subjects evident in their portraits and personal data; (b) the commitment to care evident in caregiver subjects' portraits; (c) the sense of mutuality and reciprocity that exists in the background stories of the patient and caregiver subjects; (d) and the notion of communities of care. Specific examples of each are listed below.

\section{The introspection of patient subjects seen in their portraits and personal data}

The portraits have an introspective quality that reveals patient subjects' non-verbal facial and bodily expressions and a sense of

Table 2 The mean and SD of patient subject age and the frequency and percentages of diagnostic categories $\mathrm{N}=26$

\begin{tabular}{lc}
\hline Median age in years & $\mathbf{4 6 . 4}(\mathbf{2 1 . 0 )}$ \\
\hline Diagnosis & $1(3.8)$ \\
ALS & $1(3.8)$ \\
Bowel transplant & $3(11.5)$ \\
Brain tumour & $1(3.8)$ \\
Cystic hygroma & $1(3.8)$ \\
Non-Hodgkin's lymphoma & $2(7.7)$ \\
HIV/AIDS & $6(23.1)$ \\
Head and neck cancer & $1(3.8)$ \\
Leukaemia & $1(3.8)$ \\
Stage IV osteosarcoma & $1(3.8)$ \\
Thyroid cancer & \\
& $1(3.8)$ \\
Health promotion (bariatric surgery) & $4(15.4)$ \\
Pregnancy & $3(11.5)$ \\
Infant health promotion & \\
Type & $6(23.1)$ \\
Acute & $12(46.2)$ \\
Chronic & $4(15.4)$ \\
Maternity & $4(15.4)$ \\
Health promotion &
\end{tabular}

ALS, amyotrophic lateral sclerosis 
Table 3 The mean and SD of care giver age and the frequency and percentages of caregiver roles with gender representation $\mathrm{N}=20$

\begin{tabular}{lc}
\hline Median age (years) & $\mathbf{5 1 . 4}(\mathbf{1 4 . 1 )}$ \\
\hline Relationship with patient & \\
Public health & $1(5.0)(\mathrm{F} 1 / \mathrm{M} 0)$ \\
Familial & $7(35.0)(\mathrm{F} 6 / \mathrm{M} 1)$ \\
Professional & $12(60.0)(\mathrm{F} 5 / \mathrm{M} 7$ \\
\hline
\end{tabular}

ongoing identity formation especially during transitions in health status. Despite serious illness in some cases, patients show themselves to be living through their illnesses and to be strikingly present and psychologically and spiritually intact and strong, despite physical weakness (see 'Sebron', figure 3, available online). The analysis team noted:

- Portraits have a psychological quality and are introspective in nature implying the 'interior' of subject's experiences, whether in cases of health or serious illness.

- Even when patients can't speak, they communicate through their non-verbal facial and bodily expression.

- These portraits allow the patients, in particular, to be seen as 'whole people', not fragmented by diagnoses.

- Pictures emphasise that the ill patients are 'living' through their illnesses-subjects show themselves to be remarkably 'present' and functionally more 'healthy' than might be expected given their illnesses.

These findings are supported directly by patient subject data as evidenced below:

'Roger', (figures 4 and 5, available online) a patient with ALS stated:

I saw this project as a way to put a face on ALS. When people mention Lou Gehrig's disease, the pictures that come to mind of him (are) as a baseball player, not as a patient... . I am very excited at how the portraits are progressing and am anxiously awaiting the exhibition. I hope that I will still be alive and physically able to see it. Mark Gilbert captured the essence of what I feel in his work.

(Unfortunately Roger did not live long enough to see the exhibition.)

'Glenna' (figure 6, available online) who had multiple surgeries for facial cancer as well as treatment for breast cancer said that by participating in the study: "I could see myself as others see me. It helped me to accept the way I look. Believe me I don't look like I did, but it is okay to look like that."

\section{A commitment to care evident in caregiver subjects' portraits}

Analysts noted that caregivers exhibit a sense of commitment and responsibility for care in visual qualities that show their vulnerability and solemnity as well as dependence on others that share in care giving. Specifically, analysts noted:

- Caregiver subjects' portraits reveal a sense of commitment and indications that subjects feel part of a larger mission of care giving.

- Caregiver subjects, it was pointed out by some on the analytic team, are usually awkward when they become the subject of examination-they are not the ones to be examined in their day-to-day lives. The caregiver subjects became 'vulnerable' in the sense that they allowed the artist to look at and draw them. Caregiver subjects appear thoughtful and strong in this way.

- In recruiting caregivers, investigators became mindful that care giving 'takes a village' - a wide variety of individuals including family members, professional, non-professional and community caregivers. Successful care giving depends upon co-operation of those involved.

Again, the findings above were supported directly by caregiver data as illustrated below.

'John', (figure 7, available online) a physician, was hesitant to participate and did so out of loyalty to his patient, also in the study. He said: "It [the study] prompts me to consider the relationship and connection between physician and patient at a more personal level".

'Rita', a nurse administrator stated, "I was interested in the uniqueness of capturing both sides of difficult health issues. Mark captured the spirit of the patients and caregivers... . He sees so deeply!"

'Bill', a physician subject who was also a study investigator stated, "I feel that I am a small piece in a large web ... as someone in the project and it has helped me see the vast expanse of those necessary for care."

As for the familial caregivers, they seemed especially affirmed by their participation in the study as illustrated by the following comments:

'Joey', the mother and caregiver for 'Daisy', (figure 8, available online) stated her sense of becoming a part of the community of care as her participation in the study evolved, stating, "What a joy to bond with him [MG]. What a blessing to be a part of a larger community that will be immortalised in this way."

Joey's comment about the importance of being a part of such a community was not an idle statement. Such a community is important, especially when treatment takes place over a long period as did Daisy's who was born with gastroschisis. After surgery to correct the problem, Daisy suffered complications, short gut syndrome and liver failure. Eventually she underwent small bowel, liver and pancreas transplants. These challenges, however, neither diminished the unfolding of Daisy's sparkling personality as seen in her portraits, nor her mother's caring devotion.

'Dolores', wife and caregiver of Roger who suffered from ALS stated: "I wanted to participate in the (study) because Roger valued his participation (and) we were partners in so many areas of our lives. I wanted to partner with him in this project as well."

Dolores later publicly explained that Roger wanted to help others overcome their fearfulness of people who are ill or suffering in some other way. He thought the study would help accomplish this goal while helping others learn about the importance of the personal aspects of care. As she appreciated what the study meant for her husband, Dolores realised its significance for how she was caring for him.

A sense of mutuality and reciprocity exists in the background stories of the patient and caregiver subjects

The fluidity of the boundaries of care was impressive and affirmed the universality of care and care giving. This shared identity around notions of care was strengthened by both patients' and caregivers' stated willingness to participate in the study so that others might learn from it. The analysis team noted:

- There is fluidity between care and care giving - investigators learned that a number of patients have been caregivers and caregivers have all been patients.

- The artist observed that even subjects who are children showed support to their parental caregivers. The children's matter of fact awareness of their illnesses and the way they at times would comfort and support their parents with a maturity beyond their years was striking. 
- A portrait of the only couple in the study works of patient and care giver shows their symbiosis and pulls the viewer into the intimacy of their relationship.

For example, in their personal data 'Mardi and Rob' (figure 1) addressed aspects of their portrait as a couple. Rob stated:

My wife and I are answering ... with respect to me being the patient and her being the caregiver. In fact, not long before my diagnosis she was diagnosed with breast cancer and underwent lengthy treatment. Unlike my own experience, she was able to very effectively manage her own treatment. My participation was largely in the realms of moral support, transportation and domestic support... . My wife and I were very impressed with Mark's work ... (his) ability to capture nuances (is) incredible... . We found it very insightful that Mark's work caused us to focus on aspects of each of us which we had previously not recognised.

Mardi stated:

In discussing our portraits, we both saw elements of each other which we had not seen (in life), but were very 'real.' Rob saw a vulnerability in me, which he characterised as almost a 'waifish' quality. I do see it as well ... and while we all move on, the vulnerability is part of life in the 'new normal'. In Rob I saw a reconciliation with life as it is now. We had simply not been able to make these observations in our daily life. I think Mark captured much more than the physical transformations of our Cancer journey.

\section{Implications for communities of care}

Subjects' responses to the study and their thoughts about its potential implications indicated that many thought it would prove to be important to others who might learn more about care and especially about empathy beyond their own communities. Analysts found that:

- Patient subjects responded positively to their experiences of being drawn/painted. There is intimacy and beauty in this work-for patient subjects this was a different medical experience than being poked and prodded in the usual ways. Such an experience appeared to have a therapeutic effect.

- The pictures imply a story as briefly described on the data forms, providing important contextual information and meaning that are also important for effective care to take place.

- The longer the project continued, the more vocal some subjects became in reporting the positive impact of the project and its various meanings for each of them, for example, allowing new perspectives on health and illness, helping others who will see the portraits recognise the strength in patients despite illness, providing a holistic look at care, and other findings as listed above.

Excerpts from patient subject data confirmed these finding. Many subjects mentioned on their data forms that they had enjoyed being part of the study. Comments such as those below were common:

"(I) thought it would help others... ."

"It has the potential to help others."

"Great idea-allows the public eye to view a birth of a child."

"I look forward to the exhibit. I believe these types of events can better all our understanding and inspire empathy."

One patient subject with facial cancer stated that she had dreaded coming to the hospital until entering this study, when she found herself preparing for her 'sittings' by getting dressed up and putting on makeup for the first time since undergoing multiple surgeries on her face.

\section{RESULTS FROM EXHIBITION PHASE DATA}

During the exhibition, a volunteer sample of 185 individuals from among 3000 exhibition patrons responded to the art works $(6 \%)$ by completing the gallery survey-journal questions. Most respondents completed all or most of the survey and journal sections; three individuals completed only the journal section.

The overall mean response on all survey questions that were based on the initial artistic phase findings was 4.29 with a SD of 0.55 showing strong public agreement with initial findings. This was based on a 5-point Likert scale with 1 being strongly disagree to 5 being strongly agree. The gallery survey findings are reported in table 4 .

The journal section of the gallery-survey (figure 2, back of survey, see online) asked viewers to use words to describe their responses to the portraits. In the first question $(\mathrm{Oa})$, investigators asked for respondents' impressions of the exhibition prior to seeing it based on newspaper articles and other pre-exhibition materials and broadcasts to establish respondents' expectations. Many noted having read or heard about the exhibition before seeing it. Responses to journal questions $\mathrm{Ob}$-e are summarised in table 5.

Table 4 Frequencies and percentages of the 16 public survey questions

\begin{tabular}{|c|c|c|c|c|c|c|c|c|c|c|}
\hline & $\mathbf{N}$ & 1 & 2 & 3 & 3.5 & 4 & 4.5 & 5 & Mean & SD \\
\hline 01 & 180 & $1(0.6)$ & $2(1.1)$ & $13(7.2)$ & $0(0.0)$ & $65(36.1)$ & $0(0.0)$ & $99(55.0)$ & 4.44 & 0.73 \\
\hline 02 & 181 & $2(1.1)$ & $12(6.6)$ & 49 (27.1) & $1(0.6)$ & $54(29.8)$ & $0(0.0)$ & $63(34.8)$ & 3.91 & 0.99 \\
\hline 03 & 180 & $2(1.1)$ & $4(2.2)$ & 31 (17.2) & $0(0.0)$ & $55(30.6)$ & $0(0.0)$ & $88(48.9)$ & 4.24 & 0.89 \\
\hline 04 & 180 & $1(0.6)$ & $1(0.6)$ & $16(8.9)$ & $0(0.0)$ & $44(24.4)$ & $1(0.6)$ & $117(65.0)$ & 4.54 & 0.73 \\
\hline 05 & 180 & $0(0.0)$ & $4(2.2)$ & $22(12.2)$ & $0(0.0)$ & 61 (33.9) & $0(0.0)$ & $93(51.7)$ & 4.35 & 0.78 \\
\hline 06 & 181 & $0(0.0)$ & $1(0.6)$ & $12(6.6)$ & $0(0.0)$ & $47(26.0)$ & $0(0.0)$ & 121 (66.9) & 4.59 & 0.64 \\
\hline 07 & 178 & $0(0.0)$ & $4(2.3)$ & $20(11.2)$ & $1(0.6)$ & $57(32.0)$ & $0(0.0)$ & $96(53.9)$ & 4.38 & 0.78 \\
\hline 08 & 178 & $2(1.1)$ & $4(2.3)$ & $19(10.7)$ & $1(0.6)$ & 77 (43.3) & $0(0.0)$ & $75(42.1)$ & 4.23 & 0.82 \\
\hline 09 & 177 & $2(1.1)$ & $11(6.2)$ & $50(28.3)$ & $0(0.0)$ & $50(28.3)$ & $0(0.0)$ & $64(36.2)$ & 3.92 & 1.00 \\
\hline 010 & 177 & $1(0.6)$ & $7(4.0)$ & $27(15.3)$ & $0(0.0)$ & $58(32.8)$ & $0(0.0)$ & $84(47.5)$ & 4.23 & 0.89 \\
\hline 011 & 178 & $6(3.4)$ & $12(6.7)$ & $44(24.7)$ & $0(0.0)$ & $47(26.4)$ & $0(0.0)$ & $69(38.8)$ & 3.90 & 1.10 \\
\hline 012 & 177 & $2(1.1)$ & $3(1.7)$ & $10(5.7)$ & $0(0.0)$ & 57 (32.2) & $0(0.0)$ & $105(59.3)$ & 4.47 & 0.78 \\
\hline 013 & 181 & $2(1.1)$ & $5(2.8)$ & $28(15.5)$ & $0(0.0)$ & $55(30.4)$ & $0(0.0)$ & $91(50.3)$ & 4.26 & 0.90 \\
\hline 014 & 179 & $1(0.6)$ & $2(1.1)$ & 20 (11.2) & $0(0.0)$ & $62(34.6)$ & $1(0.6)$ & $93(52.0)$ & 4.37 & 0.77 \\
\hline 015 & 180 & $0(0.0)$ & $1(0.6)$ & $2(1.1)$ & $0(0.0)$ & 33 (18.3) & $0(0.0)$ & $144(80.0)$ & 4.78 & 0.48 \\
\hline 016 & 180 & $0(0.0)$ & $0(0.0)$ & $17(9.4)$ & $0(0.0)$ & $29(16.1)$ & $0(0.0)$ & $134(74.4)$ & 4.65 & 0.65 \\
\hline Overall* & 182 & & & & & & & & 4.32 & 0.49 \\
\hline
\end{tabular}


Table 5 Language used to describe aspects of exhibition

\begin{tabular}{|c|c|c|}
\hline Question & $\begin{array}{l}\text { Five most frequently used } \\
\text { words used to describe }\end{array}$ & Frequency and percentage, $n=177$ \\
\hline $\begin{array}{l}\text { Ob What words or thoughts come to you after seeing } \\
\text { the exhibition? (A total of } 24 \text { different descriptors used in all) }\end{array}$ & $\begin{array}{l}\text { Sadness/sorrow } \\
\text { Empathy/Compassion } \\
\text { Powerful } \\
\text { Strength } \\
\text { Humanity/ resilience }\end{array}$ & $\begin{array}{l}14(7.6 \%) \\
13(7.1 \%) 7(3.8 \%) \\
12(7.1 \%) \\
12(6.5 \%) \\
\text { Each with } 8(4.4 \%)\end{array}$ \\
\hline $\begin{array}{l}\text { Qc What emotions do you see portrayed in the portraits? } \\
\text { (A total of } 38 \text { different descriptors used in all) }\end{array}$ & $\begin{array}{l}\text { Sadness/sorrow } \\
\text { Hope } \\
\text { Fear } \\
\text { Strength } \\
\text { Anger }\end{array}$ & $\begin{array}{l}57(31.0 \%) \\
47(25.5 \%) \\
31(16.9 \%) \\
24(13.0 \%) \\
20(10.9 \%)\end{array}$ \\
\hline $\begin{array}{l}\text { Od What emotions does this exhibition bring out in you? } \\
\text { (A total of } 21 \text { different descriptors used in all) }\end{array}$ & $\begin{array}{l}\text { Empathy/Compassion } \\
\text { Sadness/sorrow } \\
\text { Hope } \\
\text { Gratitude } \\
\text { Fear }\end{array}$ & $\begin{array}{l}32(17.4 \%) / 13(7.1 \%) \\
30(16.3 \%) \\
23(12.5 \%) \\
19(10.7 \%) \\
12(6.5 \%)\end{array}$ \\
\hline $\begin{array}{l}\text { Qe What is the most important message you are taking } \\
\text { away from the exhibition? }\end{array}$ & & $\begin{array}{l}\text { "A stunning and passionate glimpse into the private world of } \\
\text { patients and caregivers" "Great work." } \\
\text { "The importance of featuring medicine as an art and promoting } \\
\text { the intersection of art and medicine." } \\
\text { "Human resilience runs parallel with human vulnerability-we see, } \\
\text { but we don't see because we aren't really looking-seeing inside the } \\
\text { heart is difficult, elusive, and unsettling at times." } \\
\text { "Mark Gilberts sees in some very human ways past human } \\
\text { defences and guardedness." } \\
\text { "The pain is real." } \\
\text { "Fascinating, long overdue. A helpful corrective to high-tech } \\
\text { medicine... ." } \\
\text { "I have been back to see the exhibit several times, and each time } \\
\text { I find more ... to think about. I see more depth of emotion in me-it } \\
\text { has really made me think about what "health' really can mean." } \\
\text { "I was not expecting to gain anything from (exhibition). I was wrong." } \\
\text { "It was extremely powerful." }\end{array}$ \\
\hline
\end{tabular}

Analysts noted the oppositional nature of terms individuals sometimes used to describe the emotions they saw portrayed in subjects' portraits ( $\mathrm{Qc}$ ) and what they felt while viewing the portraits (Od) as described in table 6 .

Beyond these descriptors investigators identified three overriding themes embedded in respondents' survey-journal comments including: (a) the identity transformation that may take place among patients and caregivers; (b) the centrality of the idea of mortality; and, (c) the presence of hope, despite serious illness, and its effects on patients and caregivers. These themes are discussed below.

\section{Identity transformation among patients and caregivers}

Exhibition respondents noted that the portraits show that illness alone and even a confrontation with the spectre of death need not define one's identity and that patients' portraits show that they went on living and participating even if in an altered manner. As for caregivers-respondents registered the weight of responsibility that was etched into their facial expressions implying an identity shaped by responsiveness to others' needs.

In regard to identity, one viewer stated he was taking from the exhibition "The importance of recognising the identity of the person even when both the patient and those around (him) are overshadowed by the medical condition". Another recognised

Table 6 Examples of oppositional terms individuals used to describe both what he or she saw and felt while viewing portraits

\begin{tabular}{ll}
\hline Vulnerability and strength & Faith and cynicism \\
Empathy and fear & Joy and sadness \\
Love and anger & Hope and despair \\
Dignity and degradation & Intimacy and isolation \\
\hline
\end{tabular}

that each person has his or her own story and within the context of the story each tries to find meaning in everyday existence. In this way, people create identity and it is etched on their faces. Perhaps that is why viewers recognised that illness alone does not identify a person-that an individual can be ill, but continue living and making a contribution no matter how short life may be. How one engages with others in making sense of life and experience shapes identity for both patients and caregivers.

That viewers themselves identified with the emotional content of subjects' images was evident in the many adjectives viewers used to describe the emotional content of the portraits as discussed above. From viewers' responses it is also evident that many underwent their own transformation by viewing the exhibition. Exhibition patrons and others who have seen the portraits agree that the images are powerful and lead one to a greater appreciation of life, health, illness, care and care giving. One said of the exhibition, "It's inspiring without a word spoken", while another said, "This is truly sacred ground". One concluded, "It's complicated, which is a good thing". One viewer mentioned inserting herself into the portraits explaining, "You can tell a lot about a person from their face, but the way we perceive that face and body tell a lot about us".

Thus the transference of identity from subject to viewer, patient to caregiver and back again continues in an ongoing process involving not just the ill, but the whole community of caregivers and others in the social milieu. As one noted, "Our journeys (stories) intersect". Another said, "Illness impacts everyone and touches us at many levels". Many recognised the connectedness of patients and caregivers and the communities in which they live. One wrote, "It made me think about the words of John Donne. 'No man is an island ... never send to know for whom the bell tolls; It tolls for thee.' Our lives, our grief, our deaths are all interconnected." 


\section{The centrality of the notion of mortality}

The theme of mortality was embedded in many viewers' surveyjournal responses. Their responses revealed their realisation that they too will, if they had not already, be either a patient or a caregiver and part of the world of care. As mentioned above, for those who experience health, many expressed gratitude, but some recognised the impermanence of health in making statements such as "live for today" and "life is a gift". Another stated, "We are all faced with mortality issues-some just don't realise it yet". One viewer who perhaps realised it, admitted not wanting to think about mortality saying, "Life has its pleasing and depressing elements. This brought out the depressing parts I would rather not think about ... there is a dark side of life that I try to block out of my everyday life."

Some viewing the exhibition explained in graphic terms how the artwork arising from the PCPS helped them view not only care but life and death itself. One gallery visitor stated "The vehicle of art expresses a deep feeling not seen in the patient alone, the essence of pain and life bleed through the colours and strokes." Another viewer recalled "Lots of memories of the past with my brother. We were so alone emotionally. His doctor forbid hospice - if this exhibition saves [one] family to NOT flee the patient and caregiver-it will have been worth it. Today I am filled with gratitude. This exhibition can awaken people to LIFE and DEATH." Similarly another said, "Many years ago, I read ... that we must face death BEFORE we can truly LIVE each day as the gift it is. You have helped me SEE death and feel it... . I don't want to lose that... . I feel such appreciation."

\section{The presence of hope despite adversity and the importance of empathy and compassion}

Despite the heavier aspects of the exhibition, many viewers mentioned leaving the exhibition with a sense of hope and determination to make the most of life. One viewer stated, "It is possible for the soul of a catastrophically ill patient to soar beyond any level experienced by healthy individuals", recognising that a confrontation with mortality may be the ticket to a higher level of appreciation for life itself. Others expressed hope and thanksgiving for caregivers who rarely receive the recognition they deserve. One said, "the caregivers give me a sense of hope for humanity because of their devotion to the people they care for". Another viewer realised that "Care giving is probably as hard as being a patient". Another who had been a caregiver said, "To see the caregiver affirmed was overwhelming. How desperate we are-how little is addressed during the illness but especially the years following the death of [a] loved one." Another viewer, a nurse, drew attention to the fact that "many caregivers are living with serious disease[s] themselves". Another added, "To think of all the caregivers in this nation from [those caring for others] with dementia to childhood disabilities - at last there are faces". One noted the "blurring of distinction between caregiver and patient-we are BOTH at different times, and sometimes at the same time. But sometimes it is easier to give than receive". The importance of empathy and compassion for the ill is often acknowledged, but rarely mentioned on behalf of caregivers. This was an important finding.

\section{DISCUSSION}

One aim of portraiture is to communicate human expression, not to develop a photographic record. In focusing on human expression, MG interpreted through his drawings and paintings, the physical anatomy, expression and non-verbal presence of patients and caregivers. Expert analysis of the portraits uncovered themes relating to care and additional input from the subjects underscored certain observations. The public sample's responses confirmed the initial findings and added to their richness. Study findings all inform the basic questions we studied about the human dimensions of care and care giving in the context of health and illness.

Unstated in the original study design, but implied, was another question that we later articulated that concerned the role of the arts in clinical healthcare research. Overall, this methodology at the intersection of art and medical research yielded a wealth of insight into the nature of care and care giving and helped investigators better understand how portraiture can be used to benefit patient care, and also to facilitate public education about illness and health promotion.

One question that remains is whether the portraits, or art in general, can arouse empathy in the viewer. Empathy is the shared or resonate feeling of being in another's shoes. On first analysis it may seem that this study would support that supposition. The quotes above demonstrate that some viewers felt they understood the emotions and situations of the subjects. However, in the group discussions with the public and some of the subjects of the portraits, it was sometimes the case that the subject did not feel as viewers had imagined, a false or inaccurate empathy, if you will. One of the viewers actually made this point saying "You can tell a lot about a person from their face, but the way we perceive that face and body tell a lot about us". Nonetheless, this has value as well. Coming to terms with our own feelings with respect to health, illness, disfigurement and death provides a safe mechanism to explore and contemplate and experience from afar. This may not be precisely the same as empathy but it still serves a productive role.

A similar issue to the arousal of empathy in the viewer is whether portraiture can be viewed as therapeutic for either the viewer or the sitter. That these portraits and this project were moving for subjects and viewers appears inescapable but their actual role as a therapeutic intervention is less clear. This important question may be addressed by some of the data presented and other data collected but not presented, but clearly requires further study and analysis.

Despite the overall success of the study in diving deep into the meaning of care and care giving, health and illness, the study has limitations. Chief among these is that the confirming data from exhibition viewers represented only a small sample of gallery viewers (6\%). Investigators made surveys available, but did not actively recruit gallery respondents. The rationale for this was that investigators wanted those who did respond to the survey to do so voluntarily and thoughtfully. Those who did fill out the survey put care into their responses, lending a sense of validity to the findings. Also, four public events highlighting issues raised by the portraits were scheduled throughout the exhibition. Each event included a period for public discussion and drew an audience of 80 to 400 people. During the public discussion periods, similar comments to those included in this report were voiced supporting the validity of the sample that did respond to the gallery survey-journal as being representative of the general viewing public during the exhibition. Investigators doubt that public responses to the survey-journals were biased by gallery events as only 32 of the total 185 respondents admitted to having attended a programme and their findings were consistent with those who did not attend. It should be restated that the public data was collected to either confirm or disconfirm the original analysis that had been carried out by investigators and the analysis team during the 2-year artistic phase of the study. Certainly the public data do confirm the original findings. 
Another limitation of the study was the small number of portrait subjects included in the artistic phase of the study. Investigators recruited for breadth in the types of patient and caregiver subjects who were included in the study. This was a purposeful sample, a non-random collection of subjects. Almost all of the subjects investigators asked to participate did so, suggesting a conscious and unconscious selection process. By possibly having more subjects, or a different blend of subjects, findings may have differed. Recognising viewers' powerful identification with the subjects' portraits, however, investigators believe that the subjects' experiences were archetypical of others' human experiences across life's journey. This was further affirmed when on the opening night of the exhibition subjects came together and met each other, some for the first time. In their conversations with investigators and each other, it was apparent that subjects had shared similar deeply meaningful experiences arising from their particular situations in life. Nevertheless, as a mixed (qualitative and quantitative) method study with a small number of subjects, it is inappropriate to generalise the findings about care to other populations of patients and caregivers.

As for the role of contemporary art in seeking answers to clinical healthcare questions, investigators, subjects, exhibition viewers and collaborators at the Bemis Center for Contemporary Arts see the relationship of art and medicine as one of necessity. The exhibition's uncharted territory opened windows into the study of the nature of care and care giving that would have remained closed without the skilful and talented artist whose work helped guide this journey. Without Gilbert's sensitive observational skills to see the inner humanity, hopes, feelings, fears and vulnerabilities of patients and caregivers, investigators would not have been able to study them either for the purpose of this research. As one viewer stated, "Words are not as powerful as pictures". The portraits let us see the faces of care and care giving in all their distinctiveness and ordinariness. These faces, especially the eyes, let us glimpse into the humanity and private worlds of subjects and engage our own vulnerabilities, hopes, fears and dreams with theirs - and it is at this intersection that one is able to learn about care and care giving.

Professional caregivers are taught intellectually that healing and caring are art forms. This study using portraiture as a research medium revealed the affective dimensions of what this means. It is through the intersection of the art and science of care that those in the health professions will access a better intellectual and affective understanding of what is critical. Art can help healthcare overcome some of its narrowness of vision. As Mark Masuoka, ${ }^{7}$ Director of the Bemis Center for Contemporary Arts stated in the exhibition catalogue:

Art making is often the result of a search for a universal truth and a deeper understanding about how creativity can make a difference in society. Examining the creative process through the filter of civic engagement leads me to one inescapable conclusion: creativity kills.

Creativity kills predetermined outcomes, social complacency, apathy and the lack of imagination within our society. Art is the 21 st century weapon of choice for catalysing cultural and economic development and initiating social change. Art is the bridge that connects people by giving everyone permission to imagine the unimaginable. Creativity brings us one step closer to reviving the interdependencies between art, science and medicine in order to advocate for an equitable solution to our nation's healthcare dilemma

Hesse McGraw, ${ }^{8}$ the exhibition curator, in his catalogue essay, added another important message about the role of art in this study, stating:
French theorist Jacques Derrida ${ }^{9}$ proposed an unconditional hospitality-'Let us say yes to who or what turns up'-in effect an absolute giving up of the self to the other. Gilbert's works, due to their believability, prompt a similar effect-a marriage of the self to illness, or the responsibility of care. My hope is that all have a similar experience within the exhibition and leave somehow larger, empowered to take ownership of one's place, wherever it may be on the wellness spectrum. Then as a collective body, there will be the transformational possibility of action that recognises the right, and gift, of care.

\section{CONCLUSION}

In the final analysis, we conclude that the essence of care is what assists a person physically and emotionally during a transition in identity brought about by a change in health status. Care is like the wind, seen only by its effects in one's eyes, corporeal presence, emotional strength and sense of identity. The effect of giving care mirrors the same qualities as seen in the one(s) for whom one cares.

The PCPS has other implications as well. We have concluded that it was and remains important in three ways. First the collected portraits as a body of work will remain intact and live on into the future and may be analysed by future viewers. A tour of the works is in the planning stage. This will allow other communities to see, find meaning, and provide further evaluation data. This is consistent with subjects' motives for participation - that others would learn about care and care giving in the context of health and illness.

The study also has ongoing implications as both a research and teaching model. As a research model it can be applied to examine other aspects of health, illness and related questions. The body of work offers valuable applications for teaching the affective dimensions of caring. The arts are a powerful, untapped resource for colleagues in the health professions to imagine the humane dimensions, cultural frameworks and processes that shape human experiences of health and illness-as in this case, the essence of care is a human process of being present to one another as in Here I Am and Nowhere Else.

Finally, the study has macro level policy implications. During the summing up process investigators asked what the study did not reveal? During the exhibition data collection period, intense national debate was taking place in the US about healthcare and its reform, yet gallery survey journals showed a complete absence of data concerning the economic issues of care that dominated the press, despite there being no prohibition against doing so. While an absence of data should not be construed as evidence of absence, or that the economic aspects of care are unimportant, it does suggest that economics may be less important when directly juxtaposed to the moral and ethical dimensions of care that study subjects and the exhibition public emphasised. Investigators suggest that the findings of this study provide provisional evidence of the social construction and meaning of care and care giving. Perhaps healthcare policy discussions could be enriched and made more tangible if the arts were more often used to mobilise both professional and public audiences in articulating the social construction and meaning of healthcare and its delivery.

Acknowledgements $A$ research effort of this size happens with the assistance and support of many people. Study investigators and the artist wish to acknowledge all the patients and caregivers whose participation as subjects made the study possible. We also acknowledge those who participated in the analysis of artworks including Drs Carl Greiner, William Roccaforte, Steve Wengel, Aaron Holtz, Mark Masuoka, Hesse McGraw and Deborah Lombard whose earlier work on the 
'Saving Faces:' Art and Medicine exhibition added significant insight to this investigation. Further we wish to acknowledge Mark Masuoka and Hesse McGraw for their outstanding collaboration during the development and period of the exhibition and afterwards; Dr Brian Brim for his expert assistance in developing the gallery survey-journal; Hana Gomes and Jean Huff for their independent analysis of the exhibition qualitative data; Lisa Luebbert and Valerie Shostrom for their assistance in entering and analysing the exhibition quantitative and qualitative data.

Funding The College of Medicine and its Departments of Preventive and Societal Medicine and the Department of Otolaryngology, Head and Neck Surgery and the College of Public Health, all at the University of Nebraska Medical Center.

Competing interests None.

Patient consent Obtained.

Ethics approval This study was conducted with the approval of the University of Nebraska Medical Center Institutional Review Board.

Contributors Each of the three manuscript authors was deeply involved in all aspects of the study design, implementation, analysis, exhibition, and manuscript preparation.

Provenance and peer review Not commissioned; externally peer reviewed.

\section{REFERENCES}

1. Aita V, Lydiatt W, Gilbert M, et al. Here I am and nowhere else: portraits of care by Mark Gilbert at the intersection of art and medicine. New York University Literature Arts and Medicine Database Blog, Mar 27, 2009.

2. Rockwood K. Lending a helping eye: artists in residence at a memory clinic. Lancet Neurol 2004;3:119-23.

3. Robb N. Dalhousie medical school's artist-in-residence uses unique methods to interpret brain's mysteries. CMAJ 1994;150:1125-8.

4. Graham-Pole JR. The marriage of art and science in health care. Yale J Biol Med 2001;74:21-7.

5. Rebok G, Riley A, Forrest C, et al. Elementary school-aged children's reports of their health: A cognitive interviewing study. Qual Life Res 2001;10:59-70.

6. Heckmann M. Details from dignity to decay: facial expression lines in visual arts. Dermatol Surg 2003:29:1039-43.

7. Masuoka M. Creativity kills: reviving a civic imagination. In: McGraw H, ed. Catalogue published in conjunction with the exhibition Here I am and nowhere else: portraits of care, works by Mark Gilbert-a collaborative research effort with Virginia Aita and William Lydiatt. Omaha, Nebraska: Bemis Center for Contemporary Arts, 2009:9.

8. McGraw H. Here I am and nowhere else. In: McGraw H, ed. Catalogue published in conjunction with the exhibition Here I am and nowhere else: portraits of care, works by Mark Gilbert-a collaborative research effort with Virginia Aita and William Lydiatt. Omaha, Nebraska: Bemis Center for Contemporary Arts, 2009:61.

9. Derrida J. Of hospitality. Stanford: Stanford University Press, 2000. 